\title{
Caregivers had neighbourhood support but perceived it unsatisfactory and worsened: England Community Life Survey, 2012-2014
}

\author{
Ivy Shiue ${ }^{1,2}$
}

Received: 14 September 2015 / Accepted: 27 February 2017 / Published online: 11 March 2017

(C) The Author(s) 2017. This article is published with open access at Springerlink.com

\begin{abstract}
There has been limited research studying neighbourhood support for caregivers. Therefore, the aim of the present study was to investigate the support from neighbourhoods between both caregivers and non-caregivers in a country-wide and population-based setting. Data were retrieved from England Community Life Survey, 20122014, a new annual household survey conducted by face-toface interview since 2012, with a representative sample size of 5-6000 adult (aged 16 years and over) resident per year in England. Chi-square test and logistic regression modelling were performed to examine the variance in support from and perception toward neighbourhoods between caregivers and non-caregivers. Of 15,320 study participants, 2315 (16.0\%) had a caring responsibility. There was not much variance in feeling belonging, comfortably asking neighbours to keep keys, comfortably asking neighbours to mind children, believing neighbours pulling together and trusting people in the neighbourhood between caregivers and non-caregivers. However, caregivers seemed to be more likely to chat to neighbours (OR 0.77, 95\% CI 0.69-0.87, $P<0.001$ ) and comfortably ask neighbours to help collect grocery (OR $0.89,95 \%$ CI $0.81-0.98, P=0.023$ ). In addition, caregivers tended to perceive their neighbourhoods unsatisfactory (OR $1.17,95 \%$ CI 1.05-1.32, $P=0.007)$ and worsened in the last 2 years (OR 1.36, 95\% CI 1.22-1.51, $P<0.001)$. For future
\end{abstract}

Responsible editor: Philippe Garrigues

Ivy Shiue

ivy.shiue@northumbria.ac.uk

1 Department of Health and Life Sciences, Northumbria University, Newcastle upon Tyne, England NE7 7XA, UK

2 Alzheimer Scotland Dementia Research Centre, University of Edinburgh, Edinburgh, UK research, a longitudinal neighbourhood monitoring surveillance for all people would be suggested. For practice and policy, environmental health and nursing programs might need to extend education trainings and interventions to cover all neighbourhoods at different time points that can lessen both disease and caregiving burden and therefore optimize health and quality of life.

Keywords Neighbourhood epidemiology · Caregiver · Satisfaction · Social support · Built environment $\cdot$ Community support $\cdot$ Mental health

\section{Introduction}

\section{Evidence before this study}

Caregiving is a multi-dimensional, long and complex process. The recent two systematic reviews on dementia and stroke caregivers have summarized that patient behavioural problems, caregiver coping and personality traits and competence are the most consistent determinants of caregiver burden, depression and mental health (van der Lee et al. 2014; Rigby et al. 2009). It has been long known that social support, the perception and actuality when one is cared for, in various forms is important for everyone, and it could be particularly critical for caregivers (Vrabec 1997; Clipp and George 1990). It is used to prevent from primary and secondary poor mental health such as depression and functional impairment and to help strengthen the coping with burden of caregiving (Kate et al. 2013; Rodakowski et al. 2012; Demirtepe-Saygili and Bozo 2011; Ownsworth et al. 2010; Upton and Reed 2006; Miller et al. 2001; MaloneBeach and Zarit 1995). 


\section{Environmental factors on caregivers}

Caregivers could be exposed to various environmental hazards in the neighbourhood (Kliewer et al. 2004; Ondersma et al. 2006; Proctor et al. 2011). These risks could come in physical, mental or even financial forms that would threaten one's stability and consequently health concerns and the work performance (Brummett et al. 2005). Therefore, physical and mental supports from neighbourhoods would be important because it is the immediate living surrounding that people have been facing daily.

\section{Knowledge gap}

Neighbourhoods, as part of the built and social environments to support human living, could influence one's health and wellbeing, being physical or mental (Bender et al. 2015; Christian et al. 2015; Shiue 2015; Barnes et al. 2011: Yen et al. 2009; Diez et al. 2001). Neighbourhood perception, either on the physical surroundings or the settlement feelings, could also act as a mediator between neighbourhoods and human behaviours, health and wellbeing (Tappe et al. 2013; Martin-Storey et al. 2012; Siordia et al. 2012; Gary et al.2008). One of the dimensions for such perception would be neighbourhood satisfaction. Research has continuously shown how one's neighbourhood satisfaction could be associated with one's health conditions and health behaviours (Halbert et al. 2015; Shiue 2014; de Jong et al. 2012; Leslie and Cerin 2008; Morris et al. 2008). However, none of these studies focused on caregivers.

\section{Study aim}

Following this context, therefore, the aim of the present study was to investigate and understand the neighbourhood support among caregivers and their perception toward them in a country-wide and population-based setting.

\section{Methods}

\section{Study sample}

Data were retrieved from the UK Community Life Survey, 20122014 (more details via https://www.gov.uk/government/ collections/community-life-survey), with two study waves combined in the cross-sectional analysis. It has been a new annual household survey conducted by face-to-face interview since 2012, with a sample size of 5-6000 adult (aged 16 years and over) resident per year in England. The survey tracks the latest trends and developments across areas key to encouraging social action and empowering communities (more details via http://www. commlife.co.uk/). To ensure the results to be representative of residents (random probability sampling; robust, nationally representative data on behaviours and attitudes within communities to inform and direct policy and action in these areas) in England, quality assurance was implemented (more details via https://www.gov.uk/government/publications/faqsfor-the-community-life-survey-and-supporting-documents/ faqs-and-information-about-the-community-life-survey).

\section{Variables and analyses}

In the present study, caregivers were defined as those who had a caring responsibility (question, and do you have any caring responsibilities for a member of your immediate family or a close relative outside of your household who has any long-standing illness, disability or infirmity?). Neighbourhood support was assessed by several questions on the perception of participant's immediate neighbourhood including community support, service and amenities and satisfaction on the living area (more details on each original question via https://www.gov.uk/government/ publications/community-life-survey-questionnaire-2013-to2014). Potential covariates such as age, sex and ethnicity that could affect the carer profile were adjusted in the statistical modelling. Chi-square test and logistic regression modelling were performed to examine the variance in perception toward neighbourhoods between caregivers and non-caregivers. Venn diagrams were drawn to present the clusters between care provision and neighbourhood satisfaction. Effects were reported in odds ratios (OR) and 95\% confidence intervals (CI), with $P<0$. 05 considered statistically significant. Statistical software STATA version 13.0 (STATA, College Station, TX, USA; more details via $\mathrm{http}: / /$ www.stata.com/) was used to perform all the statistical analyses.

\section{Results}

\section{Neighbourhood support}

Of 15,320 study participants, 2315 (16.0\%) had a caring responsibility in England. People aged between 40 and 79 were more likely to provide caring than those aged under 40 (9.7\%) or above $80(9.4 \%)$, with a higher proportion in female $(17.1 \%)$ than in male $(14.8 \%)$. This included both professional caring in care homes and informal caring in the household. By ethnicity, people who classified as white $(16.2 \%)$ or none (20.0\%) were more likely to take up caring responsibility than Asian (14.8\%), black (14.1\%) or mixed (12.3\%). Table 1 lists the associations between care provision and neighbourhood support. Clearly, there was not much variance in feeling belonging, comfortably asking neighbours to keep keys, comfortably asking neighbours to mind children, believing neighbours pulling together and trusting people in the neighbourhood between caregivers and non-caregivers. 
However, caregivers seemed to be more likely to chat to neighbours (OR $0.77,95 \%$ CI $0.69-0.87, P<0.001)$ and comfortably ask neighbours to help collect grocery than non-caregivers did (OR 0.89, 95\% CI 0.81-0.98, $P=0.023$ ).

\section{Neighbourhood services and amenities}

There was also no difference in use or perception for a series of neighbourhood services or amenities including shops, pubs, parks, libraries, community centres, sports centres, youth clubs, health centres, chemists, post offices, primary and secondary schools, places of worship and public transportation (data not shown).

\section{Neighbourhood satisfaction}

Figure 1 shows the clusters among caring provision, neighbourhood satisfaction and perception on its condition over the last 2 years. Apparently, nearly $30 \%$ of the study participants either had neighbourhood dissatisfaction or perceived their neighbourhoods have gone worse in the last 2 years while the likelihood was higher in caregivers (OR $1.17,95 \%$ CI $1.05-1.32, P=0.007$ for dissatisfaction; OR $1.36,95 \%$ CI $1.22-1.51, P<0.001$ for perceiving the neighbourhoods going worsened; also see Table 1). Such situation was more common in caregivers than non-caregivers. However, the specific reasons for these were unknown due to the lack of such data in the present survey.

Table 1 Associations between care provision and neighbourhood support

\begin{tabular}{|c|c|c|c|c|}
\hline & No caregiving ( $n=12,130,84 \%)$ & Caregiving $(n=2315,16.0 \%)$ & OR $(95 \% \mathrm{CI})^{\mathrm{a}}$ & $P$ value \\
\hline \multicolumn{5}{|l|}{ Demographics } \\
\hline Age & & & & $<0.001$ \\
\hline 16-39 year & $3570(90.3 \%)$ & $382(9.7 \%)$ & - & \\
\hline $40-59$ years & $4160(79.9 \%)$ & $1047(20.1 \%)$ & - & \\
\hline $60-79$ years & $3509(82.0 \%)$ & $768(18.0 \%)$ & - & \\
\hline $80+$ years & $656(90.6 \%)$ & $68(9.4 \%)$ & - & \\
\hline Sex & & & & $<0.001$ \\
\hline Male & $5683(85.2 \%)$ & $990(14.8 \%)$ & - & \\
\hline Female & $6447(83.0 \%)$ & $1325(17.1 \%)$ & - & \\
\hline Ethnicity & & & & 0.202 \\
\hline Not classified & $60(80.0 \%)$ & $15(20.0 \%)$ & - & \\
\hline White & $10,899(83.8 \%)$ & $2108(16.2 \%)$ & - & \\
\hline Asian & $616(85.2 \%)$ & $10(14.8 \%)$ & - & \\
\hline Black & $292(85.9 \%)$ & $48(14.1 \%)$ & - & \\
\hline Mixed & $263(87.7 \%)$ & $37(12.3 \%)$ & - & \\
\hline \multicolumn{5}{|l|}{ Perception toward neighbourhood } \\
\hline Feeling belonging & $7666(83.3 \%)$ & $1534(16.7 \%)$ & $0.92(0.84-1.01)$ & 0.087 \\
\hline No & $4416(85.1 \%)$ & $774(14.9 \%)$ & 1.00 & \\
\hline Chatting to neighbours & $9358(83.1 \%)$ & $1905(16.9 \%)$ & $0.77(0.69-0.87)$ & $<0.001$ \\
\hline No & $2756(87.1 \%)$ & $407(12.9 \%)$ & 1.00 & \\
\hline Comfortably asking neighbours to keep keys & $840(83.5 \%)$ & $1692(16.5 \%)$ & $0.94(0.85-1.04)$ & 0.227 \\
\hline No & $3537(85.3 \%)$ & $612(14.8 \%)$ & 1.00 & \\
\hline Comfortably asking neighbours to mind children & $1360(86.6 \%)$ & $211(13.4 \%)$ & $1.09(0.88-1.35)$ & 0.438 \\
\hline No & $1180(86.5 \%)$ & $184(13.5 \%)$ & 1.00 & \\
\hline Comfortably asking neighbours to collect grocery & $7236(83.0 \%)$ & $1479(17.0 \%)$ & $0.89(0.81-0.98)$ & 0.023 \\
\hline No & $4823(85.5 \%)$ & $820(14.5 \%)$ & 1.00 & \\
\hline Believing neighbours pulling together & $6986(83.7 \%)$ & $1365(16.4 \%)$ & $1.02(0.93-1.12)$ & 0.676 \\
\hline No & $4403(83.9 \%)$ & $848(16.2 \%)$ & 1.00 & \\
\hline Trusting people in the neighbourhood & $9075(83.8 \%)$ & $1753(16.2 \%)$ & $1.02(0.91-1.14)$ & 0.716 \\
\hline No & $2619(84.4 \%)$ & $484(15.6 \%)$ & 1.00 & \\
\hline
\end{tabular}

${ }^{\text {a }}$ Adjusted for age, sex and ethnicity 
Fig. 1 Distribution of care provision or not and neighbourhood satisfaction among the study participants a) Venn Diagram

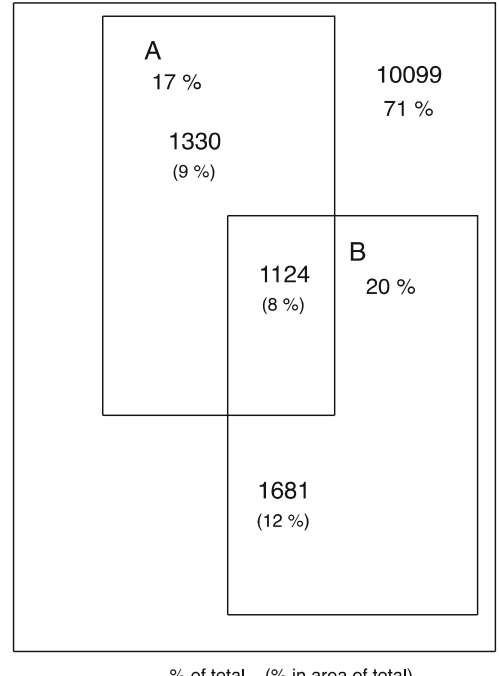

$N=14234$

A nosatisfy

$B$ areaworse

$\%$ of total $(\%$ in area of total $)$

b)

Venn Diagram

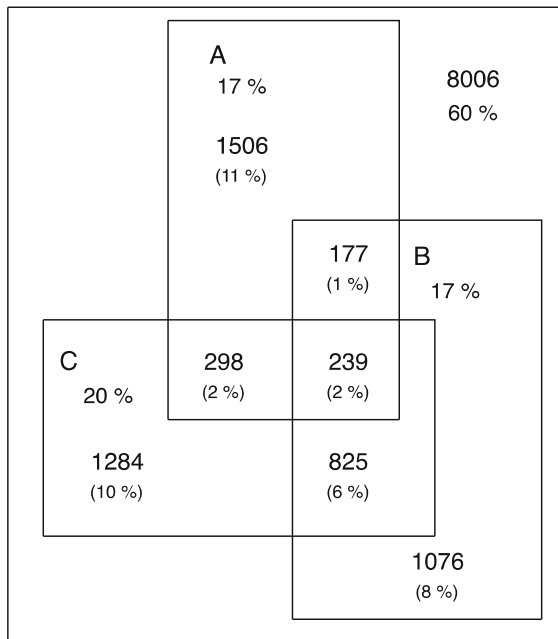

$N=13411$

A caregiving

B nosatisfy

C areaworse

$\%$ of total (\% in area of total)

15 Aug 2015 File: /Users/ivyshiue/Downloads/Combined.dta (Cr:15 Aug 2015)

\section{Discussion}

It was not surprising to see more female than male to have been caregivers, whether professionally or informally. While the caregiving has been low paid or with no pay, it would be one of the sources in widening the social inequality due to the imbalanced spending on energy, time and pay. In the present study, there was not very much variance seen in neighbourhood support for both caregivers and non-caregivers. Instead, caregivers seemed to have a slightly greater social interaction than noncaregivers had through chatting to neighbours and kindly asking them to help collect grocery. Perhaps it is such process that has made them more aware of the change of neighbourhood than non-caregivers and therefore indicated their worry about the possible worsening condition over the last 2 years, whether real or perceived.

\section{Strengths and limitations}

The present study has a few strengths. Firstly, the data were collected in a country-wide and population-based setting in the very recent years. Secondly, it was the first time to analyse the neighbourhood support for caregivers. However, there are still a few limitations that cannot be ignored. First, questions on neighbourhood support are not from a standard scale. This is because there has not been scientific research with a rigorous methodology to 
formulate. Therefore, there could be other missing aspects that were unable to be included. Second, how the neighbourhoods have gone worse was not included in the questionnaire. Therefore, the mechanism and pathway were unable to be disclosed and explained. Third, the causality cannot be established due to the cross-sectional study design in nature while the potential existing selection bias also means the research was not $100 \%$ representative through involving everyone to answer. However, it was assumed that the caring responsibilities have been constant until the household interview on neighbourhood support and perception. Taken together, future studies retaining the strengths and overcoming the limitations mentioned above with a longitudinal or qualitative approach across geographic regions to confirm such observations obtained in the present study would be warranted.

\section{Directions for future research, practice and policy}

People whom had caring responsibilities seemed to have the similar level of neighbourhood support to others who had not caring responsibilities but tended to perceive their neighbourhoods unsatisfactory and worsened in the last 2 years. For future research, establishing a longitudinal neighbourhood monitoring surveillance for all people including patients, caregivers and healthy people altogether using a scientific approach could help with documenting evidence on the link between neighbourhoods and health, wellbeing and quality of life to guide any life satisfaction improvement. In addition, constructing a standard scale on neighbourhood support together with the local police force and social care and health services by regular examination through rigorous research would be suggested. For practice and policy, environmental health and nursing programs might need to extend education trainings and interventions to cover all neighbourhoods at different time points that can lessen both disease and caregiving burden and therefore to optimize health and quality of life.

\section{Acknowledgements None.}

Compliance with ethical standards Since there were only secondary data analyses employed without any participant personal information identified by extracting statistical data from the UK Data Archive website in the present study, no further ethics approval for conducting the present study was required (more details via http:/www.ethicsguidebook.ac.uk/ Secondary-analysis-106).

Conflict of interest The author declares that she has no conflict of interest.

Open Access This article is distributed under the terms of the Creative Commons Attribution 4.0 International License (http:// creativecommons.org/licenses/by/4.0/), which permits unrestricted use, distribution, and reproduction in any medium, provided you give appropriate credit to the original author(s) and the source, provide a link to the Creative Commons license, and indicate if changes were made.

\section{References}

Barnes J, Belsky J, Frost M, Melhuish E (2011) Neighborhood characteristics and mental health: the relevance for mothers of infants in deprived English neighborhoods. Soc Psychiatry Psychiatr Epidemiol 46(12):1243-1249

Bender AM, Kawachi I, Jørgensen T, Pisinger C (2015) Neighborhood social capital is associated with participation in health checks of a general population: a multilevel analysis of a population-based lifestyle intervention - the Inter99 study. BMC Public Health 15(1):694

Brummett BH, Siegler IC, Rohe WM, Barefoot JC, Vitaliano PP, Surwit RS, Feinglos MN, Williams RB (2005) Neighborhood characteristics moderate effects of caregiving on glucose functioning. Psychosom Med 67(5):752-758

Christian H, Zubrick SR, Foster S, Giles-Corti B, Bull F, Wood L, Knuiman M, Brinkman S, Houghton S, Boruff B (2015) The influence of the neighborhood physical environment on early child health and development: a review and call for research. Health Place 33:25-36

Clipp EC, George LK (1990) Caregiver needs and patterns of social support. J Gerontol 45(3):S102-S111

de Jong K, Albin M, Skärbäck E, Grahn P, Björk J (2012) Perceived green qualities were associated with neighborhood satisfaction, physical activity, and general health: results from a cross-sectional study in suburban and rural Scania, southern Sweden. Health Place. 18(6): 1374-1380

Demirtepe-Saygili D, Bozo O (2011) Perceived social support as a moderator of the relationship between caregiver well-being indicators and psychological symptoms. J Health Psychol 16(7):1091-1100

Diez Roux AV (2001) Investigating neighborhood and area effects on health. Am J Public Health 91(11):1783-1789

Gary TL, Safford MM, Gerzoff RB, Ettner SL, Karter AJ, Beckles GL, Brown AF (2008) Perception of neighborhood problems, health behaviors, and diabetes outcomes among adults with diabetes in managed care: the translating research into action for diabetes (TRIAD) study. Diabetes Care 31(2):273-278

Halbert CH, Melvin C, Briggs V, Delmoor E, Rice LJ, Lynch C, Jefferson M, Johnson JC 2015. Neighborhood Satisfaction and Colorectal Cancer Screening in a Community Sample of African Americans. J Community Health. doi:10.1007/s10900-015-0062-9

Kate N, Grover S, Kulhara P, Nehra R (2013) Relationship of caregiver burden with coping strategies, social support, psychological morbidity, and quality of life in the caregivers of schizophrenia. Asian J Psychiatr 6(5):380-388

Kliewer W, Cunningham JN, Diehl R, Parrish KA, Walker JM, Atiyeh C, Neace B, Duncan L, Taylor K, Mejia R (2004) Violence exposure and adjustment in inner-city youth: child and caregiver emotion regulation skill, caregiver-child relationship quality, and neighborhood cohesion as protective factor. J Clin Child Adolesc Psychol 33(3):477-487

Leslie E, Cerin E (2008) Are perceptions of the local environment related to neighbourhood satisfaction and mental health in adults? Prev Med 47(3):273-278

MaloneBeach EE, Zarit SH (1995) Dimensions of social support and social conflict as predictors of caregiver depression. Int Psychogeriatr 7(1):25-38

Martin-Storey A, Temcheff CE, Ruttle PL, Serbin LA, Stack DM, Schwartzman AE, Ledingham JE (2012) Perception of neighborhood disorder and health service usage in a Canadian sample. Ann Behav Med 43(2):162-172

Miller B, Townsend A, Carpenter E, Montgomery RV, Stull D, Young RF (2001) Social support and caregiver distress: a replication analysis. J Gerontol B Psychol Sci Soc Sci 56(4):S249-S256

Morris KS, McAuley E, Motl RW (2008) Neighborhood satisfaction, functional limitations, and self-efficacy influences on physical activity in older women. Int J Behav Nutr Phys Act 5:13 
Ondersma SJ, Delaney-Black V, Covington CY, Nordstrom B, Sokol RJ (2006) The association between caregiver substance abuse and selfreported violence exposure among young urban children. J Trauma Stress 19(1):107-118

Ownsworth T, Henderson L, Chambers SK (2010) Social support buffers the impact of functional impairments on caregiver psychological well-being in the context of brain tumor and other cancers. Psychooncology 19(10):1116-1122

Proctor LJ, Van Dusen RK, Litrownik AJ, Newton RR, Davis IP, Villodas M (2011) Factors associated with caregiver stability in permanent placements: a classification tree approach. Child Abuse Negl 35(6):425-436

Rigby H, Gubitz G, Phillips S (2009) A systematic review of caregiver burden following stroke. Int J Stroke 4(4):285-292

Rodakowski J, Skidmore ER, Rogers JC, Schulz R (2012) Role of social support in predicting caregiver burden. Arch Phys Med Rehabil 93(12):2229-2236

Shiue I (2014) Prevalence and psychiatric correlates of neighbourhood satisfaction and its impact on adolescent behaviours: UK understanding society cohort, 2011-2012. Environ Res 134:390-395
Shiue I (2015) Neighborhood epidemiological monitoring and adult mental health: European Quality of Life Survey, 2007-2012. Environ Sci Pollut Res Int 22(8):6095-6103

Siordia C, Saenz J (2012) Neighborhood perception and obesity in aged Mexican Americans. J Frailty Aging 1(4):152-161

Tappe KA, Glanz K, Sallis JF, Zhou C, Saelens BE (2013) Children's physical activity and parents' perception of the neighborhood environment: neighborhood impact on kids study. Int J Behav Nutr Phys Act 10:39

Upton N, Reed V (2006) The influence of social support on caregiver coping. Int J Psychiatr Nurs Res 11(2):1256-1267

van der Lee J, Bakker TJ, Duivenvoorden HJ, Dröes RM (2014) Multivariate models of subjective caregiver burden in dementia: a systematic review. Ageing Res Rev 15:76-93

Vrabec NJ (1997) Literature review of social support and caregiver burden, 1980 to 1995. Image J Nurs Sch 29(4):383-388

Yen IH, Michael YL, Perdue L (2009) Neighborhood environment in studies of health of older adults: a systematic review. Am J Prev Med 37(5):455-463 